\title{
Biosynthesis of gold nanoparticles-peanut shell composite for catalytic reduction of methyl blue
}

\author{
Fazleen Kamaludin, Mustaffa Shamsuddin*, Suhaila Borhamdin \\ Department of Chemistry, Faculty of Science, Universiti Teknologi Malaysia, 81310 UTM Johor Bahru, Johor, Malaysia
}

* Corresponding author: mustaffa@kimia.fs.utm.my

\section{Article history}

Received 19 November 2019

Revised 9 January 2020

Accepted 5 February 2020

Published Online 15 April 2020

Graphical Abstract

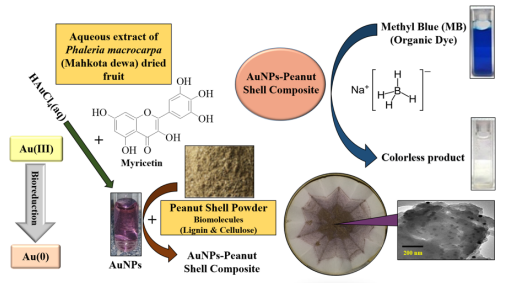

\begin{abstract}
Gold nanoparticles (AuNPs) have been recognized as an active and effective catalyst for many organic transformations. Currently, there is a growing need to develop AuNPs synthesis process that avoids the use of toxic chemicals or high energy requirements. In this research, the aqueous Phaleria macrocarpa (Mahkota dewa) dried fruit extract was used in the biosynthesis of AuNPs immobilized on peanut shell powder. The peanut shell supported AuNPs were characterized by UV-Visible spectroscopy (UV-Vis), X-ray powder diffraction (XRD), transmission electron microscopy (TEM), Fourier transform infrared spectroscopy (FTIR), thermogravimetry analysis (TGA), Nitrogen (N2) adsorption-desorption and atomic absorption spectroscopy (AAS) techniques. The biosynthesized AuNPs were characterized by the appearance of a surface plasmon resonance (SPR) band at $534 \mathrm{~nm}$ in the UV-Vis spectrum. The XRD, TEM and TGA analytical data of AuNPs/Peanut shell composite indicated that the AuNPs with face-centered cubic (fcc) crystalline shape, mostly spherical and average particle size of $20.00 \pm 4.19 \mathrm{~nm}$ were well dispersed on the peanut shell powder support. The FTIR analysis suggested that the $\mathrm{C}=\mathrm{O}$ and $\mathrm{O} \mathrm{H}$ groups in the peanut shell powder have a strong affinity to bind and stabilize the AuNPs. The BET surface area of the AuNPs/Peanut shell composite catalyst determined is $35.39 \mathrm{~m}^{2} \mathrm{~g}-1$ while the $\mathrm{BJH}$ pore volume is $0.035 \mathrm{~cm} 3 \mathrm{~g}-1$ with a pore diameter of 2.07 $\mathrm{nm}$. AAS elemental analytical data showed the Au loading is $0.03 \mathrm{mmol}$ per gram of catalyst. The catalytic performance of the AuNPs/Peanut shell composite was investigated for the reduction of aqueous methyl blue (MB) at room temperature. The reduction of MB obeyed a pseudo-first-order reaction with the highest rate constant of $0.124 \mathrm{~min}-1$. The supported AuNPs/Peanut shell composite catalyst could be easily recovered and reused for at least three times without significant loss of activity.
\end{abstract}

Keywords: Biosynthesis, gold nanoparticles, Phaleria macrocarpa, peanut shell, methyl blue

\section{INTRODUCTION}

Currently, there is a growing demand for green and environmentally techniques for the removal or decolorization of organic dyes which are considered as major water pollutants in the environment [1]. Conventional wastewater treatment procedures such as adsorption, reverse osmosis and chemical precipitation are not sufficient for their removal as these methods solely transfer pollutants from the liquid phase into solid phase where further treatment is required [2].

Gold nanoparticles (AuNPs) have attracted great attention due to their unique properties. AuNPs have been recognized as an active and effective catalyst for the catalytic reduction of organic dyes. Due to their high surface area to volume ratio, AuNPs can vividly enhance the catalytic performance [3,4]. However, agglomeration and difficulties in their separation from the reaction mixtures are some of the downsides of AuNPs. In order to prevent agglomeration and overcome the problem of their separation and recovery, immobilizing AuNPs on solid support is needed. Several inorganic solids have been used as support to disperse AuNPs such as $\mathrm{TiO} 2, \mathrm{SiO} 2, \mathrm{Fe} 3 \mathrm{O} 4$ and $\mathrm{Al} 2 \mathrm{O} 3$ [5].

Agro-waste such as peanut shell powder is potentially suitable to be used for AuNPs immobilization due to its abundance and low cost. The chemical composition of peanut shell by weight percentage is cellulose $(44.8 \%)$, hemicelluloses $(5.6 \%)$, lignin $(36.1 \%)$, crude fat $(0.1 \%)$, proteins $(5.4 \%)$ and ash content $(3.8 \%)[6]$.
Synthesizing metal nanoparticles using plant extract, which has the advantages of simple, nontoxicity, reproducibility in the production, easy scaling-up and cost-effective, has attracted wide interest in nanoparticle production [7]. To the best of our knowledge, biosynthesis of AuNPs supported on the peanut shell powder using Phaleria macrocarpa aqueous dried fruit extract has not been reported.

$P$. macrocarpa is a popular herbal medicine plant that originates from Papua Island, Indonesia, and grows throughout the year in tropical areas [8]. The phytochemical analysis had revealed that secondary metabolites such as flavonoids, glycosides, saponin glycosides, phenolic compounds, steroids, tannins, and terpenoids are present in the $P$. macrocarpa fruit extract [9]. The pericarp and mesocarp from $P$. macrocarpa fruit showed good antioxidant and anti-inflammatory activities due to the presence of phenolic and flavonoid compounds with various appreciable amounts [10].

\section{EXPERIMENTAL}

\section{Materials}

Tetrachloroauric(III) acid trihydrate (HAuCl4.3H2O) (Merck, 99.5\%), methyl blue (MB) (Aldrich) and sodium borohydride (NaBH4) (Adrich) were used as received without any further purification. All aqueous solutions were prepared using deionized water. The peanut shells were purchased from a local market while the fresh Phaleria macrocarpa fruits were obtained from a farm in Johor, Malaysia. 


\section{Preparation of peanut shell powder}

The peanut shells (Arachis hypogaea) were washed thoroughly with deionized water to remove impurities and dried under sunlight for two days. Dried peanut shells were ground and sieved using a 200 $355 \mu \mathrm{m}$ sieve. Then, the peanut shells powder was kept in an airtight glass bottle and stored under vacuum for further use.

\section{Preparation of aqueous extract of Phaleria macrocarpa dried fruit}

The Phaleria macrocarpa fruits were washed with deionized water to remove dust and impurities. The fruits were then allowed to dry at room temperature for one week. Then, $2 \mathrm{~g}$ of dried fruits were added to $200 \mathrm{~mL}$ deionized water. The extraction was carried out using the Soxhlet extraction method. The aqueous extract of Phaleria macrocarpa dried fruit was stored at $5^{\circ} \mathrm{C}$ for further use. The aqueous extract of Phaleria macrocarpa dried fruit with a concentration of $1 \%$ $\mathrm{w} / \mathrm{v}$ was used throughout the studies.

\section{Biosynthesis of AuNPs/Peanut shell composite}

Biosynthesis of AuNPs/Peanut shell composite was carried out following a procedure reported by Majumdar [11] and Yan [12] with some modification. Generally, $5 \mathrm{~mL}$ of aqueous extract of Phaleria macrocarpa dried fruit was added to $5 \mathrm{~mL}$ of HAuCl $4(3 \mathrm{mM})$. The bioreduction of $\mathrm{Au} 3+$ to $\mathrm{Au} 0$ occurred and the color of the reaction mixture changed from light yellow to deep purple within $1 \mathrm{~h}$ (Figure 1). Next, the biosynthesized AuNPs colloidal solution was added with 0.5 $\mathrm{g}$ of dried peanut shell powder, and the mixture was mechanically shaken at $140 \mathrm{rpm}$ for $24 \mathrm{~h}$. Finally, the solid product was subsequently filtered, washed several times with deionized water and dried at room temperature.

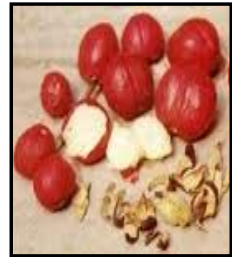

(a)

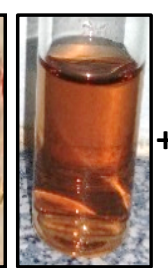

(b)

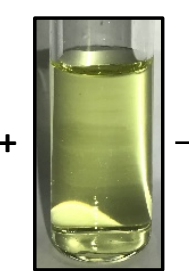

(c)

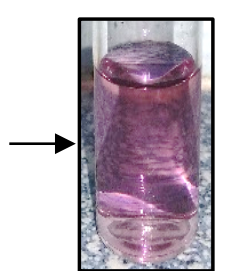

(d)

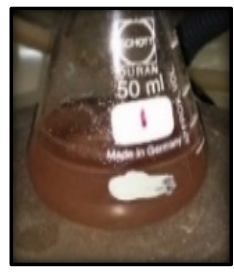

(e)

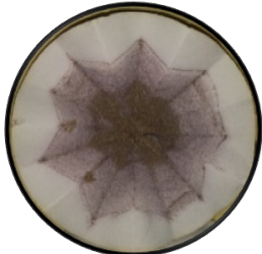

(f)
Figure 1 (a) Phaleria macrocarpa fruits; (b) Phaleria macrocarpa dried fruit extract; (c) HAuCl4 (3 mM); (d) AuNPs colloidal solution synthesized using Phaleria macrocarpa dried fruit extract; (e) Mixture of colloidal AuNPs and peanut shell powder; (f) AuNPs/Peanut shell composite.

\section{Characterization of the biosynthesized AuNPs/Peanut shell Composite}

UV-Vis spectroscopy measurements of the AuNPs were carried out on a UV-245 Shimadzu Spectrophotometer. XRD pattern of AuNPs was recorded using a Bruker D8 Advance powder diffractometer with a $\mathrm{Cu} \mathrm{K} \alpha$ radiation $(1=1.5406 \AA)$ operated at $40 \mathrm{~mA}$ and $45 \mathrm{kV}$. The diffraction pattern was recorded in the $2 \theta$ range from $10^{\circ}$ to $90^{\circ}$. TEM measurement was performed on a JEOL model 1200EX instrument operated at an accelerating voltage at $80 \mathrm{kV}$. FTIR spectroscopic analysis was carried out by a Shimadzu 8300 spectrometer in the range of 400 to $4000 \mathrm{~cm}-1$. The TGA thermogram was recorded over the temperature range of $50{ }^{\circ} \mathrm{C}$ to $1000{ }^{\circ} \mathrm{C}$ on a Mettler Toledo instrument in a nitrogen atmosphere with a ramping rate of $10^{\circ} \mathrm{C}$ min-1. The $\mathrm{N} 2$ adsorption-desorption analysis was carried out using a Thermo Finnigan Qsurf Surface Analyzer. Pore size distributions of the samples were determined from the adsorption branch of the isotherms by the
Barrett-Joyner-Hallenda (BJH) method. The measured BrunauerEmmett-Teller (BET) specific surface area was estimated for $\mathrm{P} / \mathrm{Po}$ values between 0 and 0.2. The Au loading on the AuNPs/Peanut shell composite catalyst was determined by a Perkin Elmer-AAS analyst 400 atomic absorption spectrometer.

\section{Catalytic reduction of methyl blue}

The reduction of methyl blue (MB) using sodium borohydride (NaBH4) in the presence of AuNPs/Peanut shell composite was carried out according to a reported procedure by Ganapuram [13] with some modification. In this experiment, $8 \mathrm{mg}$ of AuNPs/Peanut shell composite was added to a solution containing $1 \mathrm{~mL}$ of $\mathrm{NaBH} 4(10 \mathrm{mM})$ and $2 \mathrm{~mL}$ of $\mathrm{MB}(12 \mathrm{ppm})$ in a cuvette. The reduction of MB was monitored by using UV-vis spectroscopy in the range of 400 to $800 \mathrm{~nm}$ at every 2 minutes intervals. A similar procedure was repeated using 10 $\mathrm{mg}, 12 \mathrm{mg}$ and $14 \mathrm{mg}$ of catalyst amount. The reaction mixture of MB and $\mathrm{NaBH} 4$ devoid of the catalyst was kept as a control experiment.

\section{Recyclability test}

The recyclability test was performed by carrying out the reaction under optimized catalytic conditions. After the reaction completed, the catalyst was separated from the reaction mixture by centrifugation and washed with deionized water to remove the residue of reactant then airdried and reused again. In the subsequent run, the same amount MB and freshly prepared $\mathrm{NaBH} 4$ were used. The \% reduction of $\mathrm{MB}$ and the reaction rate constant were then calculated.

\section{RESULTS AND DISCUSSION}

\section{UV-Vis Spectra analysis}

The reduction of $\mathrm{Au}^{3+}$ ions to $\mathrm{Au}^{0}$ during the reaction with the aqueous extract of Phaleria macrocarpa dried fruit was monitored by UV-Vis spectroscopy. Figure 2 shows the UV-Vis spectrum recorded from the reaction mixture after $1 \mathrm{~h}$. An intense absorption band at $\lambda$ max $=534 \mathrm{~nm}$ is clearly seen and arises due to the surface plasmon resonance (SPR) phenomenon in the formed AuNPs. The proposed mechanism for the reduction of $\mathrm{Au}^{3+}$ ions to $\mathrm{Au}^{0}$ by virtue of the oxidation of catechol form of flavonoids found in plant extract was reported previously by our group [3].

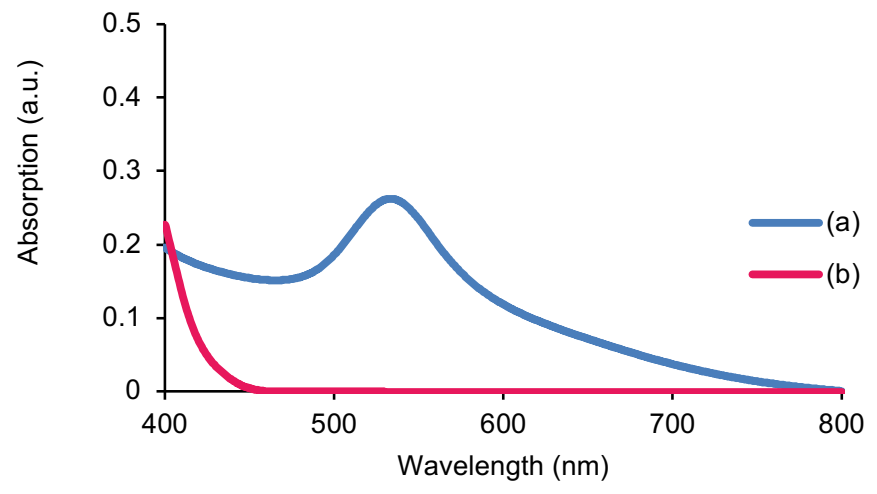

Figure 2 UV-Vis spectrum of (a) AuNPs synthesized using Phaleria macrocarpa dried fruit extract and (b) $\mathrm{HAuCl} 4$.

\section{XRD analysis}

The immobilization of AuNPs on the peanut shell was confirmed by XRD analysis. The XRD pattern in Figure 3 showed the characteristic peaks of metallic Au at $38.19^{\circ}, 44.49^{\circ}, 64.68^{\circ}$ and $77.71^{\circ}$ corresponding to the (111), (200), (220) and (311) planes of the fcc structure, respectively, which is in accordance with the standard JCPDS database \#03-065-8601. In addition, the broad and most intense peak at $22^{\circ}$ indicated the presence of the peanut shell support. It was reported previously that the XRD pattern of the peanut shell powder exhibits only broad peaks at around $10^{\circ}-35^{\circ}$ which could be assigned to the amorphous and crystalline components (cellulose, hemicellulose and lignin) $[14,15]$. 


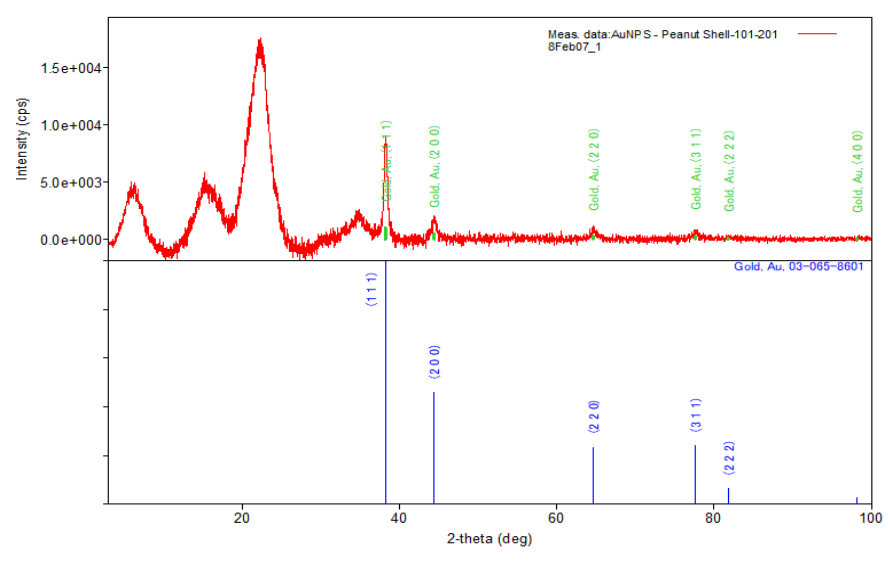

Figure 3 XRD pattern of AuNPs/Peanut shell composite (matching with Au standard JCPDS database \#03-065-8601).

\section{TEM analysis}

The size, shape and morphology of the AuNPs/Peanut shell composite were analysed by TEM technique. The TEM images in Figure 4(a), (b) and (c) showed that mostly spherical AuNPs are well dispersed on the peanut shell support. The mean diameter of AuNPs measured by image $\mathrm{J}$ software from 100 particles counts is $20.00 \pm 4.19$ $\mathrm{nm}$. The measured lattice fringe of $0.2359 \mathrm{~nm}$ corresponds to the (III) plane of fcc metallic Au as shown in Figure 4(d).

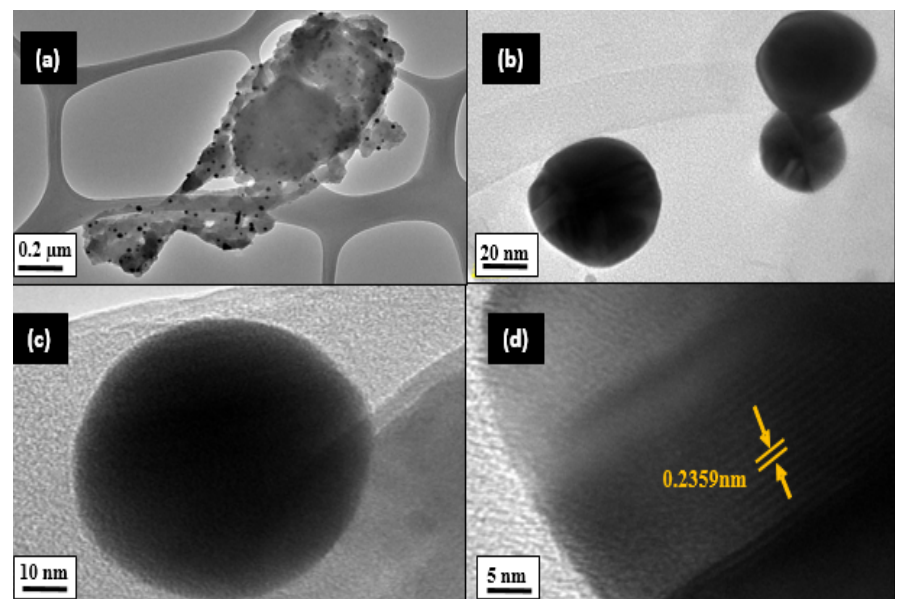

Figure 4 (a)-(c) TEM images of AuNPs/Peanut shell composite at different magnifications; (d) Measured lattice fringe of $0.2359 \mathrm{~nm}$ (correspond to the (111) plane of fcc metallic $\mathrm{Au}$ ).

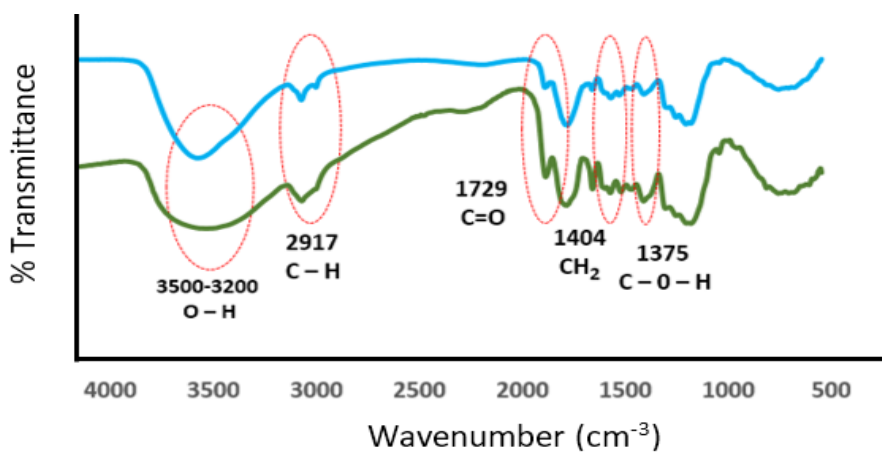

Figure $5 \mathrm{FTIR}$ spectra of (a) Peanut shell powder and (b) AuNPs/Peanut shell composite.

\section{FTIR analysis}

The FTIR spectra of the peanut shell powder and AuNPs/Peanut shell composite in Figure 5 showed the absorption bands in the region of $3400 \mathrm{~cm}^{-1}, 2900 \mathrm{~cm}^{-1}$ and $1600 \mathrm{~cm}^{-1}$ which could be assigned to the $\mathrm{O}-\mathrm{H}$ stretching vibration, $\mathrm{C}-\mathrm{H}$ stretching vibration and $\mathrm{O}-\mathrm{H}$ bending vibration, respectively. Besides, the absorption bands in the region of $1700 \mathrm{~cm}^{-1}$ and $1300 \mathrm{~cm}^{-}$in both spectra are corresponding to $\mathrm{C}=\mathrm{O}$ stretching vibration of the acetyl group from lignin and hemicelluloses and $\mathrm{C}-\mathrm{O}-\mathrm{C}$ out of plane stretching vibration of the phenyl group in lignin, respectively. This observation probably suggests that the $\mathrm{C}=\mathrm{O}$ and $\mathrm{O}-\mathrm{H}$ groups in the peanut shell powder have a strong affinity to bind with the AuNPs and therefore could stabilize the AuNPs against agglomeration in the formation of the AuNPs/Peanut shell composite.

\section{TGA analysis}

Figure 6(a) and (b) represent the TGA curves of the peanut shell powder and AuNPs/Peanut shell composite, respectively. In both samples, the weight loss at temperatures below $200^{\circ} \mathrm{C}$ can be attributed to the release of physically adsorbed water. The weight loss at temperatures from $200{ }^{\circ} \mathrm{C}$ to $400{ }^{\circ} \mathrm{C}$ in both samples is related to the decomposition of low volatile carbohydrates such as cellulose and hemicellulose $[14,15]$. At this stage, the weight loss for AuNPs/Peanut shell composite $(54.7 \mathrm{wt} \%)$ is higher than for peanut shell powder $(45.6$ $\mathrm{wt} \%$ ) which probably due to the decomposition of organic compounds of Phaleria macrocarpa dried fruit extract (capping agent) in AuNPs/Peanut shell composite [16]. The weight loss above $400{ }^{\circ} \mathrm{C}$ in both samples could be assigned to the degradation of more stable organic compounds such as lignin [14, 15]. This thermal analysis further confirmed the successful synthesis of AuNPs/Peanut shell composite and showed that the composite has good thermal stability up to $200{ }^{\circ} \mathrm{C}$.
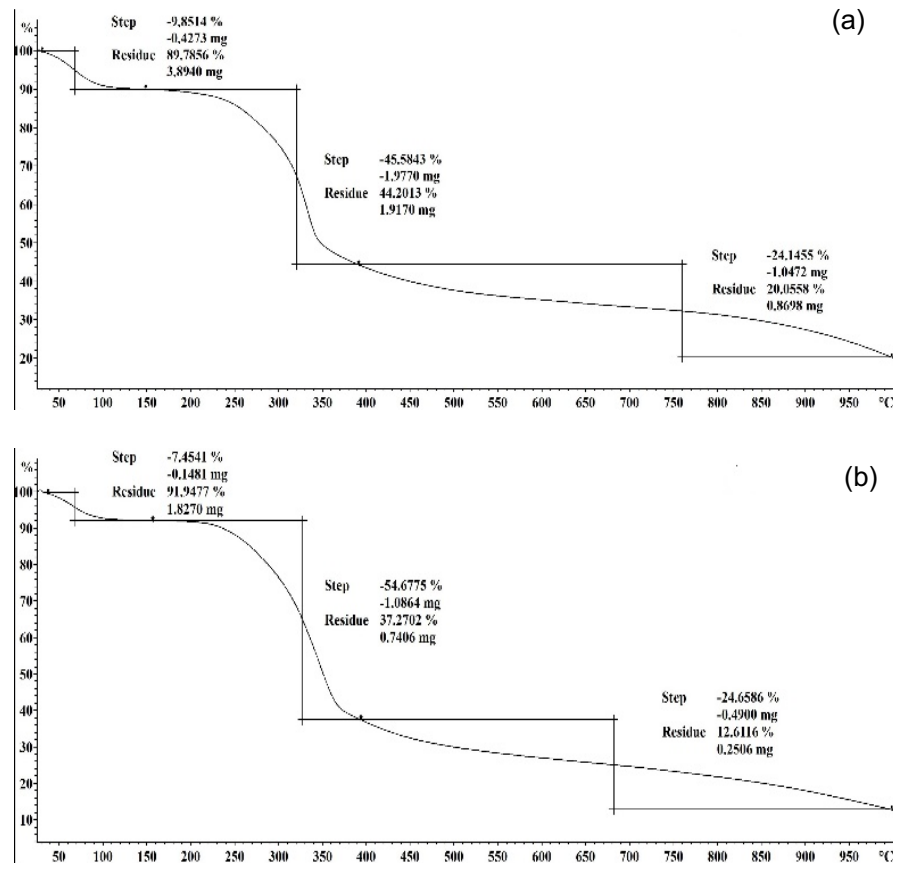

Figure 6 TGA curves of (a) peanut shell powder and (b) AuNPs/Peanut shell composite.

\section{$\mathrm{N}_{2}$ adsorption-desorption analysis}

From the $\mathrm{N}_{2}$ adsorption-desorption analysis result (Table 1), the measured BET specific surface area of peanut shell powder and AuNPs/Peanut shell composite are $13.14 \mathrm{~m}^{2} \mathrm{~g}^{-1}$ and $35.39 \mathrm{~m}^{2} \mathrm{~g}^{-1}$, respectively. Meanwhile, the pore volumes obtained from the analysis of the desorption using the BJH method (Figure 7) of peanut shell powder and AuNPs/Peanut shell composite are $0.012 \mathrm{~cm}^{3} \mathrm{~g}^{-1}$ and 0.035 $\mathrm{cm}^{3} \mathrm{~g}^{-1}$ respectively, with the corresponded pore diameter of microporous which are $2.45 \mathrm{~nm}$ and $2.07 \mathrm{~nm}$ respectively. The surface area and pore volume of the AuNPs/Peanut shell composite are higher than the surface area and pore volume of peanut shell powder, which could be attributed to the immobilization of AuNPs on the surface of peanut shell powder. Besides, the lower pore diameter in AuNPs/Peanut shell composite could probably due to the presence of a large number of small pores from the bio capped AuNPs hence further 
confirmed the successful synthesized of AuNPs/Peanut shell composite.

Table 1: Characterization of peanut shell powder and AuNPs/Peanut shell composite by $\mathrm{N}_{2}$ adsorption-desorption measurement

\begin{tabular}{lcc}
\hline & $\begin{array}{c}\text { Peanut shell } \\
\text { powder }\end{array}$ & $\begin{array}{c}\text { AuNPs/Peanut } \\
\text { shell composite }\end{array}$ \\
\hline Surface Area $\left(\mathrm{m}^{2} \mathrm{~g}^{-1}\right)$ & 13.14 & 35.39 \\
Pore Volume $\left(\mathrm{cm}^{3} \mathrm{~g}^{-1}\right)$ & 0.012 & 0.035 \\
Pore Diameter Dv(d) $(\mathrm{nm})$ & 2.45 & 2.07
\end{tabular}

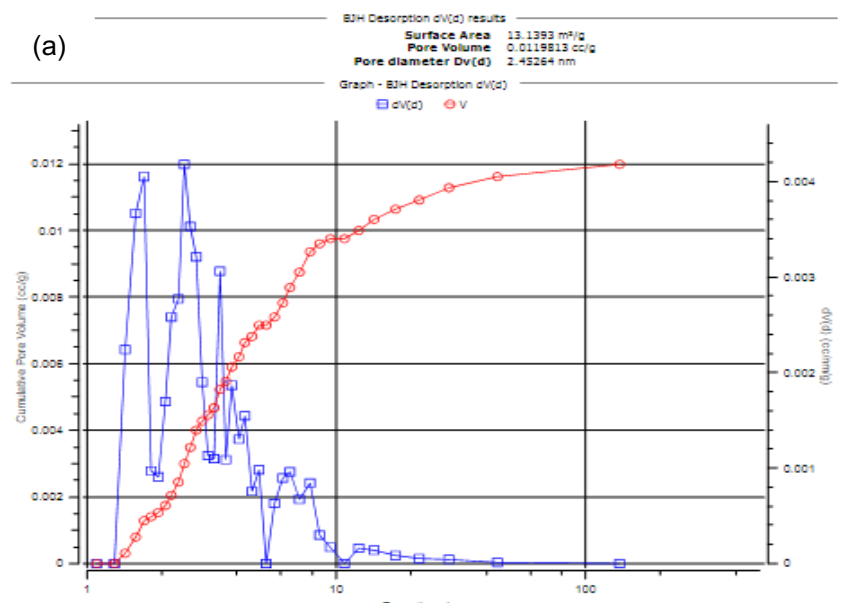

(b)

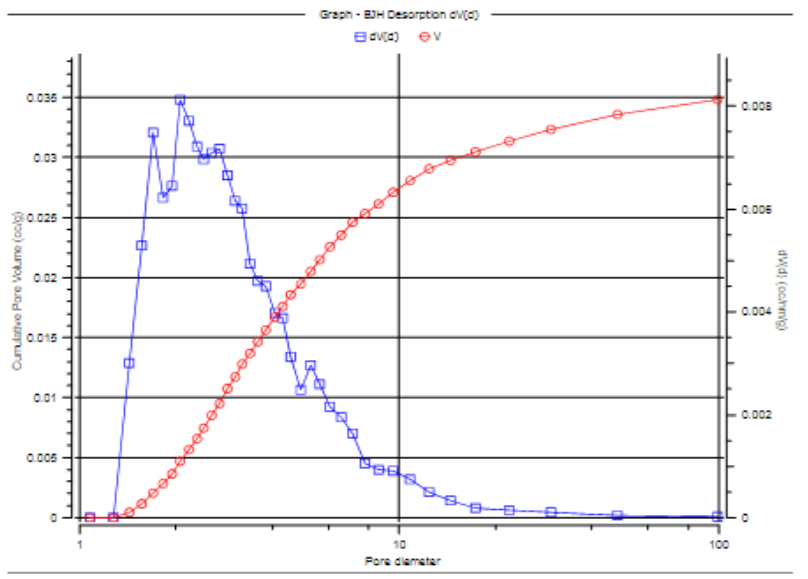

Figure 7 BJH desorption results for (a) Peanut shell powder and (b) AuNPs/Peanut shell composite.

\section{Atomic Absorption Spectroscopy (AAS) analysis}

AuNPs/Peanut shell composite $(1 \mathrm{mg})$ was digested in aqua regia solution. The obtained solution was transferred into a $50 \mathrm{~mL}$ volumetric flask, and the deionized water was added up to the mark. The appropriate concentration was obtained by dilution of solution for AAS measurement. The standard Au solutions with concentrations ranging from $1 \mathrm{ppm}$ to $5 \mathrm{ppm}$ were prepared to give a linear calibration graph. The data obtained from the AAS analysis showed that the amount of $\mathrm{Au}$ present is equivalent to a loading of $0.03 \mathrm{mmol}$ of Au per gram of AuNPs/Peanut shell composite catalyst.

\section{Catalytic reduction of methyl blue by AuNPs/Peanut shell composite}

The biosynthesized AuNPs/Peanut shell composite has been tested as a catalyst in the reduction of methyl blue (MB) using sodium borohydride $(\mathrm{NaBH} 4)$ as a reducing agent. Figure 8 shows the time- dependent UV-Vis spectra for the reduction of MB. As seen in Figure 8(a), with the addition of the catalyst, the fading of the blue color of MB was observed along with the decrease in UV-Vis absorbance. Meanwhile, in the absence of a catalyst (Figure 8(b)), only a slight decrease in UV-Vis absorbance was observed after $1 \mathrm{~h}$, thus suggesting that no significant reduction has occurred without the presence of a catalyst.
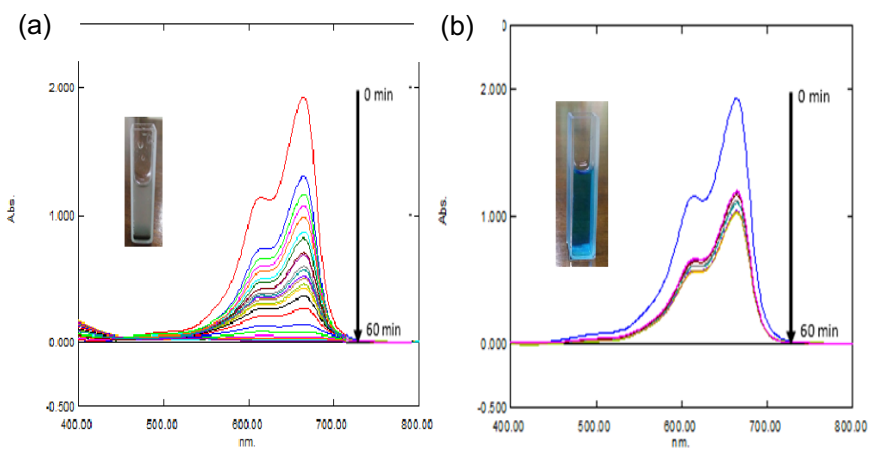

Figure 8 Time-dependent UV-Vis spectra for the catalytic reduction of MB with (a) $12 \mathrm{mg}$ AuNPs/Peanut shell catalyst and (b) without catalyst (control experiment) (Reaction conditions: 1:25 reactant:reductant mole ratio, $R T, 1 \mathrm{~h}$ ).

The catalytic reduction of MB was carried out in excess of $\mathrm{NaBH}_{4}$ concentration as compared to MB. Therefore, the concentration of $\mathrm{NaBH}_{4}$ is considered constant, and the reaction rate $(\mathrm{k})$ of the reduction only dependent on MB concentration. Hence, the rate was assumed to follow the first-order kinetics and was calculated by using the following kinetic equation:

$$
\left.\mathrm{k}=-\underline{\ln \left(\mathrm{A}_{t}\right.} \underline{\underline{\mathrm{A}}} \underline{\mathrm{A}_{0}}\right)
$$

where $\mathrm{k}$ is rate constant and $\mathrm{t}$ is reaction time. The rate constant $(\mathrm{k})$ was calculated from the slope of the plot of $\ln \left(\mathrm{A}_{t} / \mathrm{A}_{0}\right)$ versus the reaction time ( $\mathrm{t}$ ) as displayed in Figure 9. The rate constant of reduction that using $12 \mathrm{mg}$ AuNPs/Peanut shell catalyst (Figure 9(a)) is $0.124 \mathrm{~min}^{-1}$, which is higher than those control experiment $\left(0.0053 \mathrm{~min}^{-1}\right)$ (Figure 9(b)) suggesting that the catalyst is effective in removing the MB.

(a)

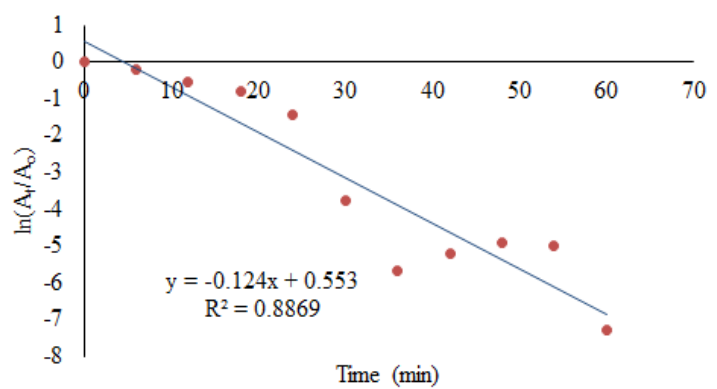

(b)

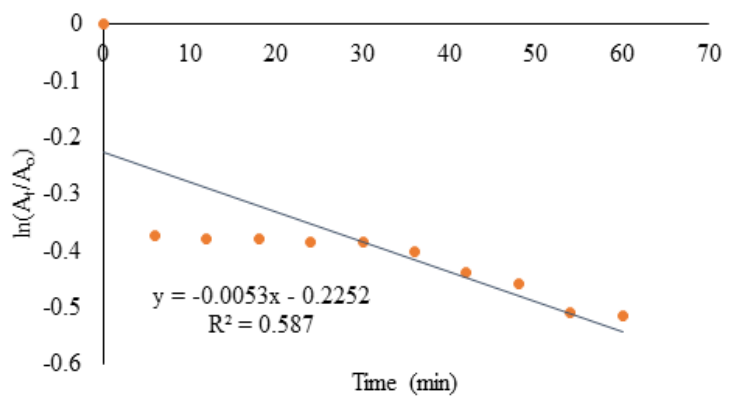

Figure 9. The plot of $\ln (A t / A 0)$ versus time $(t)$ for the catalytic reduction of MB with (a) $12 \mathrm{mg} \mathrm{AuNPs/Peanut} \mathrm{shell} \mathrm{catalyst} \mathrm{and} \mathrm{(b)} \mathrm{without} \mathrm{catalyst}$ (control experiment).

The amount of catalyst used was varied in order to investigate the effect of catalyst amount on the reaction rate constant and $\%$ reduction 
of methyl blue. Figure 10 shows the rate constant and \% reduction of methyl blue as a function of catalyst amount. As can be seen, the reaction rate constant and methyl blue reduction increased from 0.050 min- 1 to 0.124 min- 1 and $96.8 \%$ to $99.6 \%$, respectively, as the amount of catalyst increased from $8 \mathrm{mg}$ to $12 \mathrm{mg}$. This probably due to the increase of the available Au active sites. However, further increase of the catalyst amount from $12 \mathrm{mg}$ to $14 \mathrm{mg}$ caused the decreased in the reaction rate constant and methyl blue reduction from 0.124 min- 1 to $0.043 \mathrm{~min}-1$ and $99.6 \%$ to $99.4 \%$, respectively, which probably due to the aggregation of the catalyst causing a decrease in the number of available $\mathrm{Au}$ active site [17]. Therefore, $12 \mathrm{mg}$ was chosen as the optimum catalyst amount for the further recyclability test.

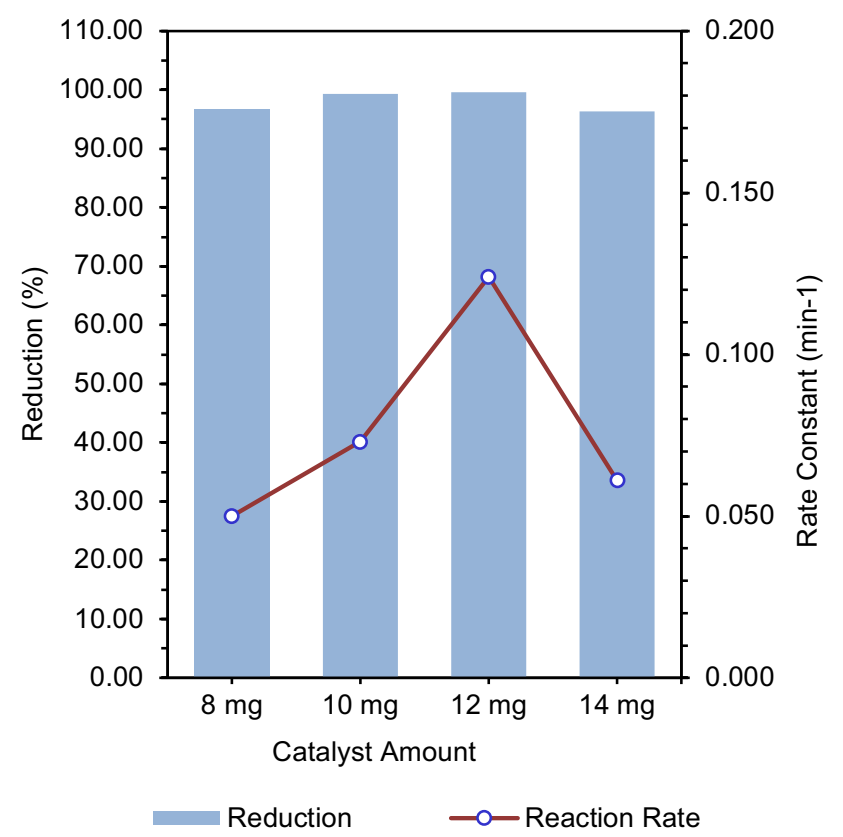

Figure 10 Effect of catalyst amount on the reaction rate constant and \% reduction of methyl blue (Reaction conditions: 1:25 reactant:reductant mole ratio, $\mathrm{RT}, 1 \mathrm{~h}$ )

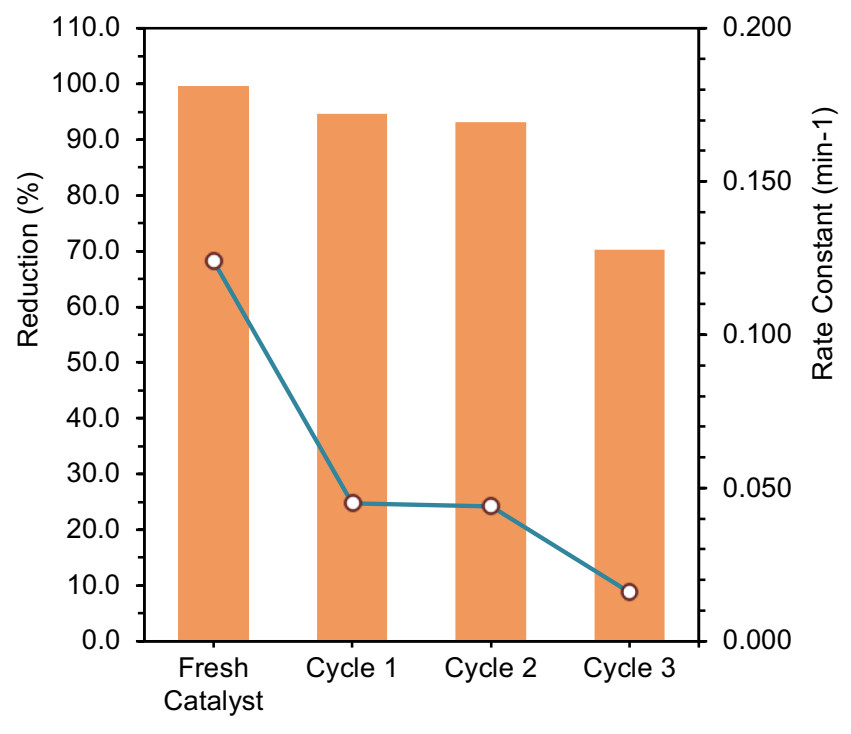

$$
\text { Reduction } \quad-0 \text { - Reaction Rate }
$$

Figure 11 Recycle test of AuNPs/Peanut shell catalyst. (Reaction conditions: $12 \mathrm{mg}$ AuNPs/Peanut shell, (1:25 reactant:reductant mole ratio, $\mathrm{RT}, 1 \mathrm{~h})$.

\section{Recyclability test}

The results for the recyclability test of AuNPs/Peanut shell catalyst is illustrated in Figure 11. The \% reduction of methyl blue for fresh cycle, cycle 1 , cycle 2 and cycle 3 are $99.6 \%, 94.6 \%, 93.2 \%$ and $70.3 \%$, respectively. It was observed that the catalyst could be recycled at least three times without significant loss in activity, thus indicates the remarkable stability of the catalysts. Hence, it is proposed that the plant biomass plays an important role as a reducing and capping agent, as well as efficient support to avoid the AuNPs from agglomeration.

\section{CONCLUSIONS}

A simple and environmentally friendly method for the synthesis of AuNPs using aqueous extract of Phaleria macrocarpa dried fruit as reducing and capping agent was demonstrated in this study. This biosynthesis completed within $1 \mathrm{~h}$ at room temperature. The biosynthesized AuNPs were immobilized on peanut shell powder. The XRD, TEM, FTIR, TGA and $\mathrm{N}_{2}$ adsorption-desorption analyses confirmed the formation of crystalline spherical AuNPs with the average particle size of $20.00 \pm 4.19 \mathrm{~nm}$ supported on the peanut shell. The AuNPs/Peanut shell composite shows strong catalytic activity in the reduction of methyl blue with the highest rate constant of $0.124 \mathrm{~min}$ 1 achieved within 1 hour, thus suggesting that the catalyst is effective in removing the methyl blue. The catalyst could be easily recovered and reused for at least three times without significant loss of activity.

\section{ACKNOWLEDGMENT}

The authors thank the Ministry of Higher Education Malaysia and Universiti Teknologi Malaysia for their financial support through a Research University Grant (vote number 18H52) and Ministry of Education Malaysia (MOE) for providing a scholarship to Fazleen Kamaludin.

\section{REFERENCES}

[1] Holkar, C. R., Jadav, A. J., Pinjari, D. V., Mahamuni, N. M., Pandit, A. B. (2016). A critical review on textile wastewater treatments: Possible approaches. Journal of Environmental Management, 182, 351-366.

[2] Rajasulochana, P., Preethy, V. (2016). Comparison on efficiency of various techniques in treatment of waste and sewage water - A comprehensive review. Resource-Efficient Technologies, 2(4), 175-184.

[3] Borhamdin, S., Shamsuddin, M., Alizadeh, A. (2016). Biostabilised icosahedral gold nanoparticles: synthesis, cyclic voltammetric studies and catalytic activity towards 4-nitrophenol reduction. Journal of Experimental Nanoscience, 11(7), 518-530.

[4] Fierascu, R. C., Ortan, A., Avramescu, S. M., Fierascu, I. (2019). Phytonanocatalysts: Green synthesis, characterization, and applications. Molecules, 24(19), 3418-3452.

[5] a) Gogoi, N., Borah, G., Gogoi, P. K., Chetia, T. R. (2018). $\mathrm{TiO}_{2}$ supported gold nanoparticles: An efficient photocatalyst for oxidation of alcohol to aldehyde and ketone in presence of visible light irradiation. Chemical Physics Letters, 692, 224-231.

b) Vadakkekara, R., Chakraborty, M., Parikh P. A. (2012). Catalytic performance of silica-supported silver nanoparticles for liquid-phase oxidation of ethylbenzene. Industrial \& Engineering Chemistry Research, 51(16), 5691-5698.

c) Poreddy, R., García-Suárez, E.J., Anders Riisager, A., Kegnæs, S. (2014). Silver nanoparticles supported on alumina-a highly efficient and selective nanocatalyst for imine reduction. Dalton Transaction, 43(11), 4255-4259.

[6] Sareena, C., Sreejith, M. P., Ramesan, M. T., Purushothaman, E. (2014). Biodegradation behaviour of natural rubber composites reinforced with natural resource fillers-monitoring by soil burial test. Journal of Reinforced Plastics and Composites, 33(5), 412-429.

[7] Sorbiun, M., Mehr, E. S., Ramazani, A., Malekzadeh, A. M. (2018). Biosynthesis of metallic nanoparticles using plant extracts and evaluation of their antibacterial properties. Nanochemistry Research, 3(1), 1-16.

[8] Altaf, R., Asmawi, M. Z. B., Dewa, A., Sadikun, A., Umar, M. I. (2013). Phytochemistry and medicinal properties of Phaleria macrocarpa (Scheff.) Boerl. extracts. Pharmacognosy Reviews, 7, 73-80.

[9] Lay, M. M., Karsani, S. A., Mohajer, S., Abd Malek, S. N. (2014). Phytochemical constituents, nutritional values, phenolics, flavonols, flavonoids, antioxidant and cytotoxicity studies on Phaleria macrocarpa (Scheff.) Boerl fruits. BMC Complementary and Alternative Medicine, 14, 152.

[10]Hendra, R., Ahmad, S., Oskoueian, E., Sukari, A., Shukor, M. Y. (2011). Antioxidant, anti-inflammatory and cytotoxicity of Phaleria macrocarpa 
(Boerl.) Scheff fruits. BMC Complementary and Alternative Medicine, 11(1), 110.

[11]Majumdar, R., Bag, B. G., Maity, N. (2013). Acacia nilotica (Babool) leaf extract mediated size-controlled rapid synthesis of gold nanoparticles and study of its catalytic activity. International Nano Letters, 3(1), 53.

[12] Yan, W., Chen, C., Wang, L., Zhang, D., Li, A. J., Yao, Z., Shi, L. Y.(2016). Facile and green synthesis of cellulose nanocrystal-supported gold nanoparticles with superior catalytic activity. Carbohydrate Polymers, 140, 66-73.

[13]Ganapuram, B. R., Alle, M., Dadigala, R., Dasari, A., Maragoni, V., Guttena, V. (2015). Catalytic reduction of methylene blue and Congo red dyes using green synthesized gold nanoparticles capped by salmalia malabarica gum. International Nano Letters, 5(4), 215-222.

[14]Thota, S. P., Badiya, P. K., Guragain, Y. N., Vadlani, P. V., Pandey, M., Dandamudi, R. B., Ramamurthy, S. S., Belliraj, S. K. (2018). Innovative consortia of micro and macro fungal systems: cellulolytic enzyme production from groundnut shell biomass and supportive structural analysis. Journal of Sustainable Bioenergy Systems, 8(03), 47-66.

[15]Dolatkhah, Z., Mohammadkhani, A., Javanshir, S., Bazgir, A. (2019). Peanut shell as a green biomolecule support for anchoring Cu2O: A biocatalyst for green synthesis of 1,2,3-triazoles under ultrasonic irradiation. BMC Chemistry, 13(1), 97.

[16]Aljabali, A. A. A., Akkam, Y., Al Zoubi, M. S., Al-Batayneh, K. M., AlTrad, B., Abo Alrob, O., Alkilany A. M., Benamara M., Evans, D. J. (2018). Synthesis of gold nanoparticles using leaf extract of Ziziphus zizyphus and their antimicrobial activity. Nanomaterials, 8(3), 174.

[17] Ghaly, H. A., El-Kalliny, A. S., Gad-Allah, T. A., El-Sattar, N. E. A., Souaya, E. R. (2017). Stable plasmonic Ag/AgCl-polyaniline photoactive composite for degradation of organic contaminants under solar light. $R S C$ Advances, 7(21), 12726-12736. 